Provided for non-commercial research and education use.

Not for reproduction, distribution or commercial use.

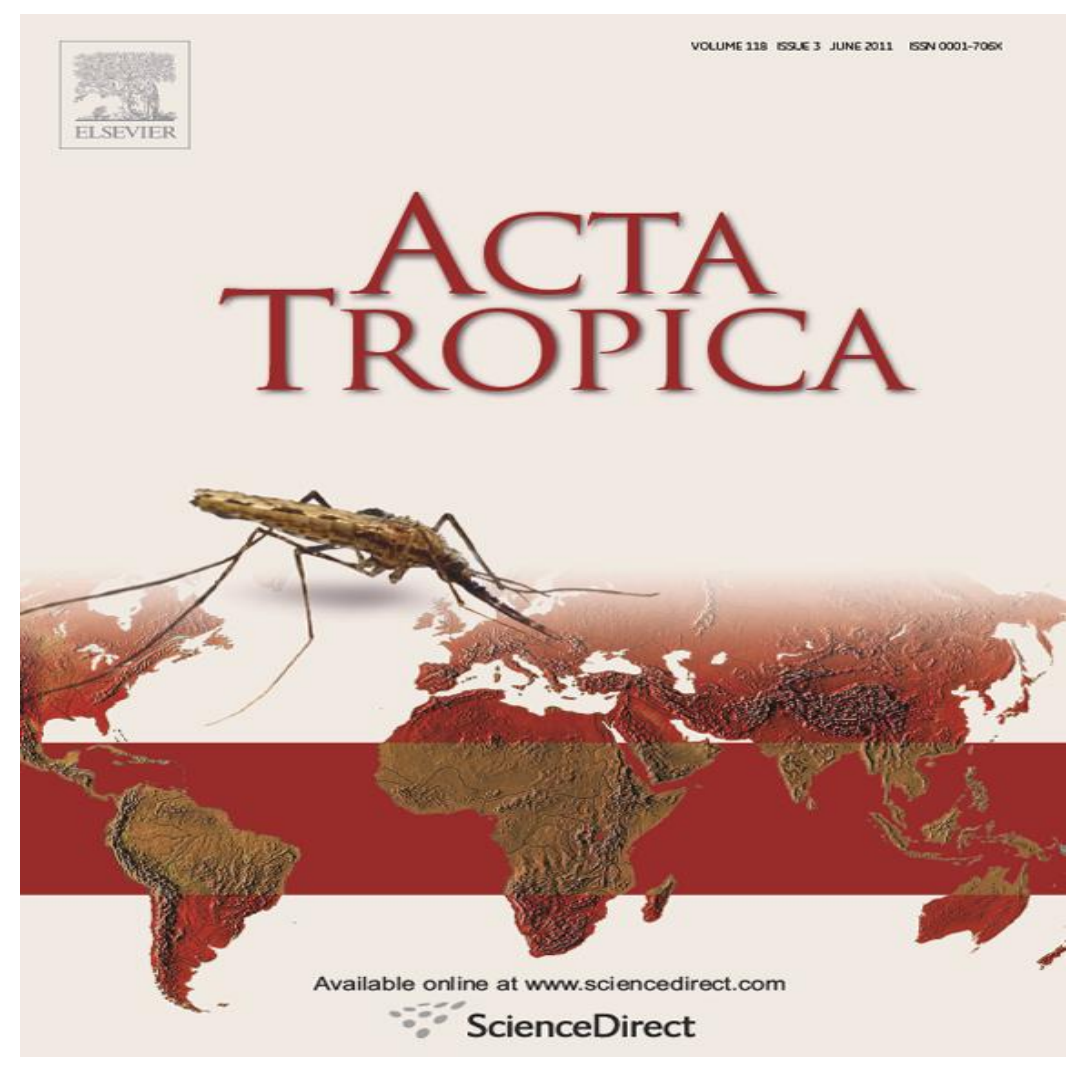

This article appeared in a journal published by Elsevier. The attached copy is furnished to the author for internal non-commercial research and educational use, including for instruction at the author's institution and sharing with colleagues.

Other uses, including reproduction and distribution, or selling or licensing copies, or posting to personal, institutional or third party websites are prohibited.

In most cases authors are permitted to post their version of the article (e.g. in Word or Tex form) to their personal website or institutional repository. Authors requiring further information regarding Elsevier's archiving and manuscript policies are encouraged to visit:

http://www.elsevier.com/copyright 


\title{
Socio-environmental conditions, intestinal parasitic infections and nutritional status in children from a suburban neighborhood of La Plata, Argentina
}

\author{
María I. Gamboa ${ }^{\mathrm{a}, *}$, Graciela T. Navone ${ }^{\mathrm{a}}$, Alicia B. Orden ${ }^{\mathrm{b}}$, María F. Torres ${ }^{\mathrm{c}, \mathrm{d}}$, \\ Luis E. Castro ${ }^{c}$, Evelia E. Oyhenart ${ }^{c, e}$ \\ a Centro de Estudios Parasitológicos y de Vectores (CEPAVE, CCT La Plata-CONICET), calle $2 N^{\circ}$ 584, La Plata 1900, Argentina \\ ${ }^{\mathrm{b}}$ Instituto de Desarrollo e Investigaciones Pediátricas (IDIP) (MS/CIC-PBA), Argentina \\ "Instituto de Genética Veterinaria "Ing. Fernando Noel Dulout" (IGEVET), FCV, UNLP-CCT CONICET, Argentina \\ d Facultad de Filosofía y Letras, UBA, Argentina \\ e Cátedra de Antropología Biológica IV, FCNyM, UNLP, Argentina
}

\section{A R T I C L E I N F O}

\section{Article history:}

Available online 3 July 2009

\section{Keywords:}

Intestinal parasites

Children

Socio-environmental factors

Nutritional status

\begin{abstract}
A B S T R A C T
We analyzed intestinal parasitic infections in children aged 1-12 years from a poor neighborhood in La Plata, Argentina, and determined the correlations with their nutritional status and socio-environmental conditions. We performed parasitological analyses with anal brushed technique (for Enterobius vermicularis eggs) and fecal samples, employing the techniques of Ritchie, Carles Barthelemy and Willis. The worm burdens of nematodes were estimated by means of Kato Katz technique. Low weight-for-age (underweight), height-for-age (stunting) and weight-for-height (wasting) were calculated based on the 5th centile of the WHO 2006 (children under 5) and CDC 2000 (older children and adolescents) growth references. We also analyzed samples of soil, water, and canine feces and surveyed other domestic and environmental data using structured questionnaires to each child's parents. To associate the parasitological, anthropometric and socio-environmental data, a categorical analysis of principal components (catPCA) was conducted. In the first axis of catPCA, the correlations among socio-environmental variables showed a gradient of "relative welfare". The eigenvectors showed the most influential variables in the analysis were promiscuity (0.0765), father's education $(-0.741)$, crowding $(0.727)$, wastewater disposal $(-0.658)$, mother's education $(-0.574)$, and flooding $(-0.409)$. The $85 \%$ of children were parasitized and $79.6 \%$ polyparasitized. The $27.7 \%$ of children had deficit in some nutritional status indicator, being the stunting the most prevalent deficit (16.8\%). There also found parasites in $42 \%$ of the dog feces, $53 \%$ of the soil samples, and non-pathogenic amoebae in the water samples. The SEV was mainly associated with geohelminths and stunting, especially among the poorest children. The study evidences that living conditions are variable within this population. Part of these variations could be linked to the differences in the extent to which parents are able to use their scant resources to influence their children's morbidity. Further studies need to be done from a qualitative approach.
\end{abstract}

(C) 2009 Elsevier B.V. All rights reserved.

\section{Introduction}

In Latin America, where the movement of rural populations to urban areas has been both rapid and highly visible, about $85-90 \%$ of the population lives in cities (PAHO, 1998; Díaz Malásques, 2002). This movement has not always been successful since it has been usually limited by the lack of employment opportunities (Almandoz, 2008). One of the consequences has been an increase in the number of poor urban people who have to live in slums where they are denied basic amenities such as potable water, electricity, and proper sanitation (Ruel, 2000). This circumstance produces an

\footnotetext{
* Corresponding author. Tel.: +54 221 4233471; fax: +54 2214232327.

E-mail address: inesgamboa@cepave.edu.ar (M.I. Gamboa).
}

epidemiological framework that is characterized by a high prevalence of infectious diseases, such as parasitoses (Thompson, 2001; Gamboa et al., 2003).

In La Plata, the capital city of the Province of Buenos Aires (Argentina), only $28 \%$ of the inhabitants have basic infrastructural services. In contrast, $62 \%$ of the population lives in a suburban area called Gran La Plata (EPH, 2003). Many of these marginal settlements are located in flood-prone areas, which circumstance favors soil contamination and consequently the transmission of diseases by food contaminated with pathogens, e.g., Escherichia coli, Vibrio cholerae; Giardia lamblia, Ascaris lumbricoides, Hymenolepis nana (Gamboa, 1999; Basualdo et al., 2000). Chronic infections and multiple parasitoses exacerbate this situation and cause a significant increase of anemia, growth retardation, and vulnerability to other diseases (Stephenson and Holland, 1987). Thus Bethony et al. 
(2006) observed that parasitized children exhibited short heightfor-age, cognitive deficits, and lower performances at school. For this reason, further research involving these socio-environmental aspects is needed in such high-risk areas. The aim of this work was therefore to analyze socio-environmental characteristics, intestinal parasitoses and nutritional status in children from a poor suburban neighborhood of La Plata, the capital city of Buenos Aires.

\section{Materials and methods}

"El Paligüe" settlement, $3 \mathrm{~km}$ south of the urban center of La Plata, is characterized by precarious housing built on government lands with limited access to public services. There we found two soup kitchens, a NGO sponsored by a religious entity operating in the neighborhood. Children aged 0-6 years attend one of these soup kitchens and are there for $6-10 \mathrm{~h}$ per day; young people aged 6-18 years attend the other one after school. The children are served two daily meals (breakfast/lunch or lunch/afternoon snack); school and recreational activities are also take place. The soup kitchens serve a variety of meals often consisting of casserole dishes; such as rice stews, potatoes, and pasta along with some fruit. Both soup kitchens supply weekly medical services.

The sample comprised 55 boys and 64 girls, aged 1-12 years (49 between 1 and 3 years old, 37 between 4 and 6 years old, 19 between 7 and 9 years old and 14 between 10 and 12 years old). The children participated in the study following written consent by their parents or legal guardians. The health status of the participants was assessed by the physician attending the soup kitchens. Any children with chronic diseases or pathological conditions were excludes from the study.

Research protocols followed the principles regarding the privacy of personal data outlined in the Helsinki Declaration and successive modifications as well as those under Argentine National Law (No. 25.326).

\subsection{Socio-environmental data}

The data recorded were obtained from observations of the neighborhood, inspections of the soup kitchens, and visits to the children's homes. The persons in charge of the children's homes were interviewed by means of a structured questionnaire to evaluate several socio-environmental characteristics and measure housing variables through information regarding the structural qualities, amenities and family characteristics (Table 1).

\subsection{Parasitological data}

For screening intestinal parasites, fecal samples of children were collected for 5 successive days in wide-mouthed screw-capped jars containing $10 \%(\mathrm{v} / \mathrm{v})$ formalin. The sedimentation technique of Ritchie and Carles Barthelemy as well as the flotation procedure of Willis was used for the coproparasitological analysis to gather the largest amount of parasitological information (Navone et al., 2005). To detect eggs of Enterobius vermicularis the perianal zone was brushed each morning using sterile gauzes. This procedure was carried out for 5 mornings, immediately after getting up. They were stored in a container with $25 \mathrm{ml}$ of a solution of formalin $10 \%$. The containers with the gauzes (brushed anal) were vigorously shaken. Then, the liquid was centrifuged at $400 \times g$ during $10 \mathrm{~min}$ and the obtained sediment was observed by optical microscope. When nematode eggs were found, a fresh fecal sample was required to determine the worm burden (WHO, 1991).

Dog feces were collected and processed by the techniques mentioned above. Soil samples were taken by means of the techniques recommended by Dada and Lindquist (1979). After Tween-80
Table 1

Socio-environmental characteristics.

\begin{tabular}{|c|c|}
\hline Characteristic & Abbreviation \\
\hline $\begin{array}{l}\text { Structural qualities and amenities } \\
\text { Building materials } \\
\text { Low quality prefab } \\
\text { Fired brick masonry } \\
\text { Makeshift materials } \\
\text { Other }\end{array}$ & $\mathrm{BM}$ \\
\hline $\begin{array}{l}\text { Floor type } \\
\text { Cement } \\
\text { Dirt }\end{array}$ & FT \\
\hline $\begin{array}{l}\text { Pavement } \\
\text { Flooding }\end{array}$ & $\begin{array}{l}\text { PV } \\
\text { FL }\end{array}$ \\
\hline $\begin{array}{l}\text { Drinking water (main source) } \\
\text { Piped water system } \\
\text { Protected well } \\
\text { Rain tank storage }\end{array}$ & DW \\
\hline $\begin{array}{l}\text { Wastewater disposal } \\
\text { Sewerage system } \\
\text { Septic tank }\end{array}$ & WD \\
\hline $\begin{array}{l}\text { Waste collection } \\
\text { Electricity } \\
\text { Gas (piped) } \\
\text { Kitchen separated from the rest of the house } \\
\text { Television } \\
\text { Freezer } \\
\text { Oven } \\
\text { Domestic animals }\end{array}$ & $\begin{array}{l}\text { WC } \\
\text { EL } \\
\text { G } \\
\text { KI } \\
\text { TV } \\
\text { FR } \\
\text { OV } \\
\text { A }\end{array}$ \\
\hline $\begin{array}{l}\text { Family characteristics } \\
\text { Crowding (persons by room) } \\
\text { Promiscuity }\end{array}$ & $\begin{array}{l}\text { CR } \\
\text { PR }\end{array}$ \\
\hline $\begin{array}{l}\text { Education } \\
\text { Mother's education } \\
\text { Universitary } \\
\text { High school } \\
\text { Elementary }\end{array}$ & ME \\
\hline $\begin{array}{l}\text { Father's education } \\
\text { Universitary } \\
\text { High school } \\
\text { Elementary }\end{array}$ & $\mathrm{FE}$ \\
\hline $\begin{array}{l}\text { Work } \\
\text { Mother's work } \\
\text { Employed } \\
\text { Unskilled worker } \\
\text { Informal worker } \\
\text { Autonomous worker } \\
\text { Unemployed }\end{array}$ & MW \\
\hline $\begin{array}{l}\text { Father's work } \\
\text { Employed } \\
\text { Unskilled worker } \\
\text { Informal worker } \\
\text { Autonomous worker } \\
\text { Unemployed }\end{array}$ & \\
\hline
\end{tabular}

solubilization, these samples were processed by a technique of concentration by flotation (Navone et al., 2006). To screen the water, five samples of drinking water were taken from the children's homes and from the soup kitchens. The techniques applied were those recommended by the American Public Health Association (1999). For each sample, we passed 10001 of tap water via a hose directly through a propylene filter with pore of $1 \mu \mathrm{m}$ of size. After sampling the filter was placed into a sterile plastic bag. In the laboratory filter was manually triturated and immersed in a solution of Tween-80 $0.1 \%(\mathrm{v} / \mathrm{v})$. After $24 \mathrm{~h}$, the dismembered filter was discarded and the liquid separated and concentrated by centrifugation in $200 \mathrm{ml}$ recipients at $1200 \times \mathrm{g}$ for $10 \mathrm{~min}$. Sediment was transferred to centrifuge tubes and centrifuged at $1200 \times \mathrm{g}$ during 


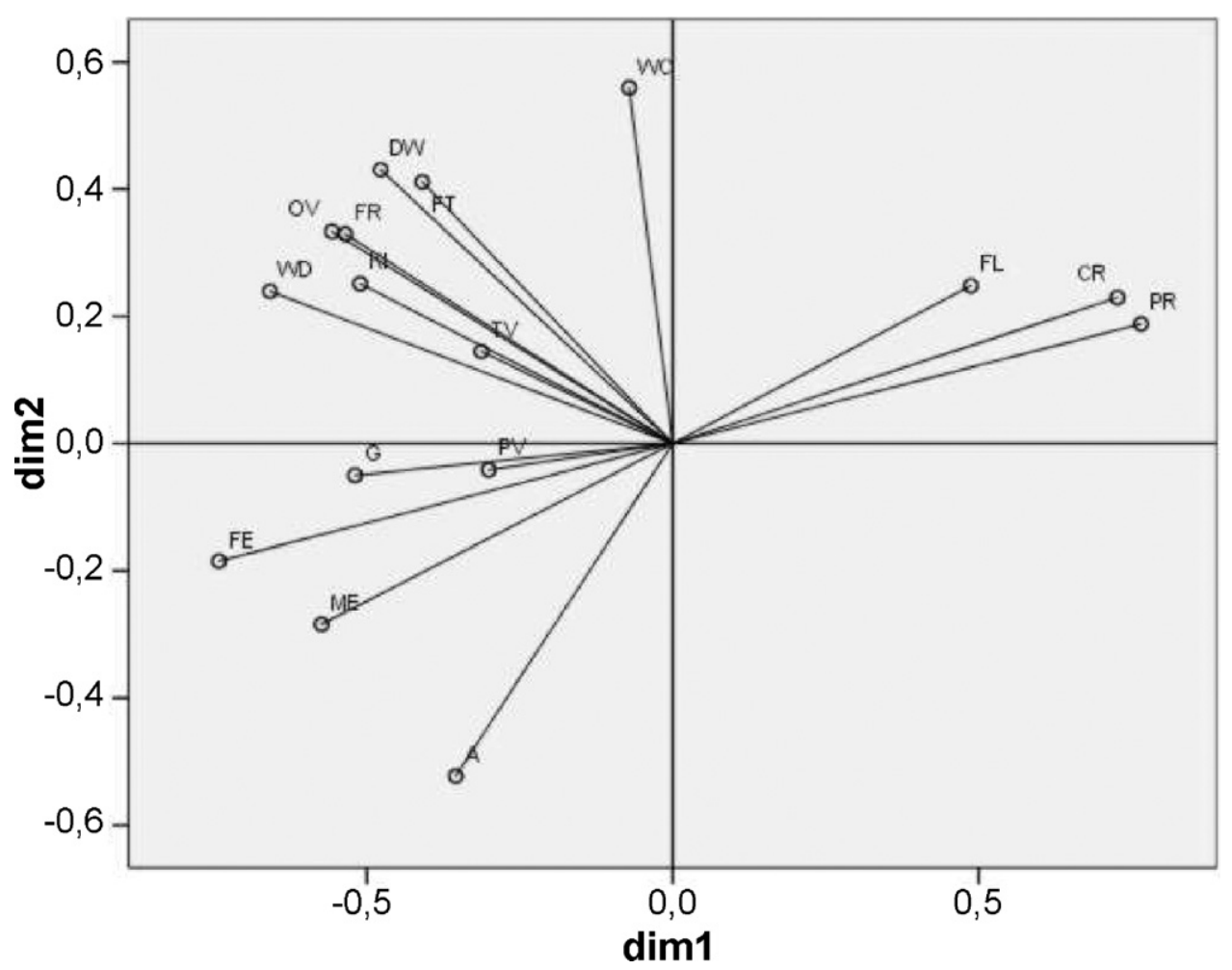

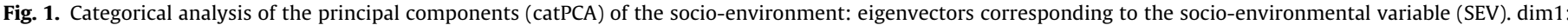
axis 1; dim2: axis 2. Multiple nominal variables (nonlinear) were excluded.

10 min. Then, the total sediment was observed by optical microscope.

\subsection{Anthropometric data}

The anthropometric measurements were made according to standard procedures (Lohman et al., 1998) by one of the authors (M.F.T.). We copied each child's age from his/her own identification cards and calculated the value in years in decimals by subtracting the child's recorded birth date from the date of measurement. Body weight $(\mathrm{kg})$ was measured on a portable baby scale (precision, $10 \mathrm{~g}$ ) until 2 years of age and on a portable digital scale (precision, $50 \mathrm{~g}$ ) from 2 to 12 years of age, with the subjects lightly clothed (with an estimate of the weight of the clothes then subtracted). Height $(\mathrm{cm})$ was measured with a pediometer (precision, $1 \mathrm{~mm}$ ) until 2 years of age and with a portable vertical anthropometer (precision, $1 \mathrm{~mm}$ ) in the older children. The accuracy of the measurement was checked by computing the technical error of measurement (TEM), calculated as the square root of the sum of squared differences between two repeated measurements, divided by two times the number of subjects measured (here 15). The TEM values were below the maximum acceptable reported by Ulijaszek and Kerr (1999). Data were analyzed through the use of the MGRS (WHO, 2006) and CDC (Kuczmarski et al., 2000) growth references. Low weight-for-age (underweight), height-for-age (stunting), and weight-for-height (wasting) were calculated using the 5th centile as the cut-off point.

\subsection{Statistical analysis}

The use of questionnaires to characterize the socioenvironmental conditions of a household and the neighborhood led to a difficulty in summarizing such a sizeable bulk of information in a few interpretable indicators. The techniques available to reduce the dimensionality of a multivariate matrix have been traditionally restricted to the nature of the variables to be used. The principal components analysis is a common and relatively simple technique, easily accessible in any statistical software, which requires multivariate normality of original variables (Krzanowski and Marriott, 1994). In this study, we used an ordering technique described by Meulman et al. (2004) on categorical principal component analysis (catPCA). The result of this form of analysis is a new low-dimensional space of variation in which variables and observations can be projected. The interpretation of this space will have the following characteristics: (1) in well fitted models, individuals with similar profiles will be close together, (2) the most "average" individuals will be the nearest to the origin of the coordinates, (3) nominal variants can be observed as the centroids of individuals who share this attribute, (4) the distance between the centroids and the origin indicates the discriminant capacity of each variable, (5) the categories of different variables that are shared by many individuals are close together in the space, and (6) the proximity or separation of the points' subclouds according to different categories from a variable, indicates their discriminant power.

The scores obtained for the first axis from catPCA projection were used as a variable of socio-environmental (SEV) quality for subsequent analysis. Correlations between the presence of each parasite species and the scores, as well as nutritional status and scores, were assessed by a logistic-regression model.

The weight of each parasite species over the total species observed was assessed by means of the equitability index (Morales and Arelis Pino, 1987). To determine the relationship between pairs of parasites, the Chi-square test $\left(\chi^{2}\right)$ was utilized and the Odds Ratio was determined with $95 \%(\mathrm{CI}=95 \%)$ confidence intervals. Data were processed by SPSS 12.0 and Epi info 2000 (CDC, Epidemiology Program Office, Division of Public Health Surveillance and Informatics). 
Table 2

Eigenvalues from categorical analysis of the principal components (catPCA).

\begin{tabular}{|c|c|c|c|c|c|c|c|}
\hline \multirow[t]{3}{*}{ Axe } & \multirow[t]{3}{*}{ Cronbach's alpha } & \multicolumn{6}{|c|}{ Variance accounted } \\
\hline & & \multicolumn{2}{|c|}{ Multiple nominal variables } & \multicolumn{2}{|c|}{ Non-multiple variables } & \multirow[t]{2}{*}{ Total (eigenvalue) } & \multirow[t]{2}{*}{$\%$ of variance } \\
\hline & & Total & $\%$ of variance & Total & $\%$ of variance & & \\
\hline 1 & 0.875 & 1.356 & 45.194 & 4.503 & 28.144 & 5.859 & 29.06 \\
\hline 2 & 0.591 & 0.701 & 23.356 & 1.570 & 9.813 & 2.271 & 12.02 \\
\hline Total & $0.907^{\mathrm{a}}$ & $1.028^{\mathrm{b}}$ & $34.275^{\mathrm{b}}$ & 6.073 & 37.956 & $7.101^{\mathrm{c}}$ & $37.375^{c}$ \\
\hline
\end{tabular}

a Based in total autovalues.

b Mean on the dimensions.

c Autovalues and percentage of variance are not equal to the sum on the dimensions because of the nominal multiple variables.

\section{Results}

\subsection{Socio-environmental analysis}

In $82 \%$ of the cases, both parents were in charge of the family; while single, separated, or widowed mothers headed the remaining $18 \%$. Fifty-eight percent of the parents did not have a formal job, and $38 \%$ had only an incomplete primary education. On average, each house was inhabited by six persons, 3.6 of them were children. Sixty-five percent of the children lived in crowded homes, and $62 \%$ shared their bed. In addition, $38 \%$ had inadequate sanitary installations (latrines). Drinking water was not available in $24 \%$ of the houses, while 29\% lacked refuse-collection service.

The eigenvalues from catPCA are shown in Table 2 . The first axe represented $45.2 \%$ of the total variance (Cronbach's alpha $=0.875$ ). Correlations between socio-environmental variables in the first axe

Table 3

Prevalence of parasite species in the total sample of children from "El Paligüe" neighborhood.

\begin{tabular}{lrr}
\hline Parasite & No. & $\%$ \\
\hline Protozoa & 89 & 74.8 \\
Blastocystis hominis & 58 & 48.7 \\
Giardia lamblia & 43 & 36.1 \\
Entamoeba coli & 28 & 23.5 \\
Enteromonas hominis & 25 & 21.0 \\
Endolimax nana & 25 & 21.0 \\
Chilomastix mesnili & 6 & 5.0 \\
Helminths & 37 & 31.1 \\
Hymenolepis nana & 15 & 12.6 \\
Enterobius vermicularis & 39 & 32.8 \\
Ascaris lumbricoides & 25 & 21.0 \\
Trichuris trichiura & 10 & 8.4 \\
Strongyloides stercoralis & 1 & 0.8 \\
Monoparasitized & 21 & 20.4 \\
Polyparasitized & 82 & 79.6 \\
Total & 102 & 85.7 \\
\hline
\end{tabular}

Table 4

Associations between the socio-environmental variable (SEV) and the intestinal parasitoses through a logistical regression model.

\begin{tabular}{lrlrll}
\hline Species & \multicolumn{1}{c}{ B } & E.T. & Wald & Sig. & $\operatorname{Exp}(B)$ \\
\hline G. lamblia & 0.085 & 0.192 & 0.194 & 0.660 & 1.088 \\
Ch. mesnili & 0.723 & 0.530 & 1.863 & 0.172 & 2.061 \\
B. hominis & 0.197 & 0.186 & 1.121 & 0.290 & 1.217 \\
E. hominis & -0.399 & 0.223 & 3.198 & 0.074 & 0.671 \\
E. coli & 0.200 & 0.224 & 0.799 & 0.371 & 1.221 \\
E. nana & -0.347 & 0.222 & 2.434 & 0.119 & 0.707 \\
A. lumbricoides & 1.276 & 0.346 & 13.615 & $0.000^{*}$ & 3.581 \\
T. trichiura & 1.285 & 0.523 & 6.043 & $0.014^{*}$ & 3.615 \\
E. vermicularis & 0.154 & 0.199 & 0.600 & 0.438 & 1.167 \\
S. stercoralis & -0.158 & 0.974 & 0.026 & 0.871 & 0.854 \\
H. nana & 1.413 & 0.456 & 9.591 & $0.002^{*}$ & 4.110 \\
Parasitized & 0.633 & 0.264 & 5.771 & $0.016^{*}$ & 1.884 \\
\hline
\end{tabular}

$p<0.05$.
Table 5

Percentage of parasitic forms in soil, water, and canine samples.

\begin{tabular}{lccc}
\hline Parasite & Soil $(n=28)$ & Water $(n=5)$ & Canine $(n=12)$ \\
\hline Toxocara canis/Toxocara cati & 32 & 0 & 16 \\
A. lumbricoides & 28 & 0 & 16 \\
Trichuris vulpis & 0 & 0 & 8 \\
Ancylostoma caninun & 11 & 0 & 16 \\
Taenia spp./Echinococcus spp. & 7 & 0 & 0 \\
Larvae of soil nematodes & 53 & 80 & 0 \\
Entamoeba coli & 0 & 66 & 0 \\
Iodamoeba butschlii & 0 & 20 & 0 \\
Other amoebae & 0 & 66 & 0 \\
Total & 53 & 100 & 41 \\
\hline
\end{tabular}

Table 6

Prevalence of undernutrition and estimations of coefficients of the general linear model against SEV.

\begin{tabular}{lrrllll}
\hline & $\%$ & \multicolumn{1}{c}{$B$} & S.E. & Wald & Sig. & $\operatorname{Exp}(B)$ \\
\hline Underweight & 8.4 & 0.959 & 0.480 & 3.985 & 0.046 & 2.608 \\
Wasting & 2.5 & -0.856 & 0.579 & 2.203 & 0.138 & 0.423 \\
Stunting & 16.8 & 0.656 & 0.296 & 4.921 & 0.027 & 1.926 \\
\hline
\end{tabular}

of the catPCA defined as SEV showed a gradient of "relative welfare". The score values ranked from the best (negative values) to the worst (positive values) socio-environmental conditions (Fig. 1). The eigenvectors from catPCA showed that the most influential variables in the analysis were promiscuity (0.0765), father's education (-0.741), crowding (0.727), wastewater disposal $(-0.658)$, mother's education $(-0.574)$, and flooding $(-0.409)$, among others.

\subsection{Parasitological results}

The $85.7 \%(n=102)$ of the analyzed fecal samples were positive for parasite species and/or not pathogenic organisms. Anal swab technique revealed the presence of $E$. vermicularis. The more prevalent species were Blastocystis hominis, G. lamblia, E. vermicularis and A. lumbricoides. Trichuris trichiura and $H$. nana were lower (Table 3). About $20.4 \%$ of the positive cases were monoparasitized and $79.6 \%$ polyparasitized in which the co-infection reached a maximum of 7 species. There were significant correlations for the co-existence of several pairs of species: E. coli-G. lamblia ( $\chi^{2}$ Mantel-Haenszel $\left.=7.0 ; p<0.01\right)$; Endolimax nana-B. hominis ( $\chi^{2}$ Mantel-Haenszel $\left.=9.41 ; p<0.01\right)$; E. nana-E. coli $\left(\chi^{2}\right.$ Mantel-Haenszel $=7.37 ; p<0.01) ;$ E . nana-Enteromonas hominis $\left(\chi^{2}\right.$ Mantel-Haenszel $\left.=18.31 ; p<0.01\right) ;$ A. lumbricoides $-E$. coli $\left(\chi^{2}\right.$ Mantel-Haenszel $=10.53 ; p<0.01)$; . lumbricoides-T. trichiura $\left(\chi^{2}\right.$ Mantel-Haenszel $=10.0 ; p<0.01)$; and A. lumbricoides-H. nana $\left(\chi^{2}\right.$ Mantel-Haenszel $=6.8 ; p<0.01$ ).

The degree of equitability (I. Eq.) in the distribution of parasite species was high (I. Eq. $=0.9$ ), indicating that there was no dominance of some species over others. The $75 \%$ of samples by Kato Katz were light infections of $A$. lumbricoides $(X=3285 \mathrm{epg})$ and $T$. 
trichiura $(X=972 \mathrm{epg}), 13.3-6 \%$ were moderate infections of $A$. lumbricoides ( $X=35,800 \mathrm{epg}$ ) and . trichiura $(X=7590 \mathrm{epg})$ and $6 \%$ were high infections of $A$. lumbricoides ( $X=75,610 \mathrm{epg}$ ). The worm burden was not correlated with the age of the host $(p>0.05)$. The correlation between the number of parasitic species and the SEV was significant (Spearman correlation coefficient $=0.187, p=0.04$ ). Table 4 shows the statistical correlations between parasitoses and the SEV.

Positive results for eggs of some species were obtained in dog feces (42\%) and soil samples (53\%). Cysts of Entamoeba coli and Iodamoeba butschlii were detected in filtered water (Table 5).

\subsection{Anthropometric results}

Rates of underweight, stunting and wasting reached $8.4 \%, 16.8 \%$ and $2.5 \%$, respectively. The correspondence between the SEV and the indicators of nutritional status - adjusted according to the logistic-distribution model [logit (undernourishment) $=b_{0}+b \mathrm{SEV}$ ] - showed a significant association with underweight and stunting (Table 6).

\section{Discussion}

The urban social strata show inequalities so that the lower income inhabitants have higher rates of undernourishment than those from rural areas (Ruel, 2000). However, the precarious impoverished intra-urban strata are habitually considered as relatively homogenous. Within such groups, where poverty is commonly shared by all the inhabitants, differences regarding parasitoses and nutritional status become strongly related to local socio-environmental conditions. In this study we found a gradient in living conditions, which is related to variations in nutritional status and parasite prevalences.

Socio-environmental variables such as crowding, promiscuity, flooding, wastewater disposal, and education of father were the factors that certainly aggravate the health condition in these children. These variables were associated with the presence of parasitic infections, mainly geohelminths, polyparasitoses, and undernutrition.

More than $80 \%$ of children were parasitized, mostly polyparasitized. This polyparasitism was evident in relation to geohelminths - ranged from $20 \%$ to $8 \%$ - which showed positive associations between $A$. lumbricoides-T. trichiura and A. lumbricoides-H. nana. Such sinergism has been observed in rural populations, where the worm burden of $A$. lumbricoides is higher in individuals infected with $T$. trichiura and vice versa (Needham et al., 1998). A. lumbricoides is regarded as an indicator both of fecal contamination in soil and of coprofagic habits of canines (Traub et al., 2003). Human defecation practices found in this study jointed to the role of dogs in the transmission of geohelminths warranted the infections with A. lumbricoides and the presence of its eggs in the soil from the surroundings of the homes and recreational areas.

On the other hand, the eggs of Trichuris vulpis in canine feces constitute a possible zoonotic risk factor (Mirdha et al., 1998; Dunn et al., 2002). Likewise, the finding of Toxocara canis and Ancylostoma caninun may produce syndrome of visceral, ocular, neurological, or cutaneous larva migrans in children, as reported by some studies in La Plata (Venturini and Radman, 1988; Minvielle et al., 2003; Córdoba et al., 2002). Furthermore, cestode (tape-worm) eggs from the Taeniidae family could be from Echinococcus spp. or Taenia spp., which genera are considered to be of high zoonotic risk as observed by Sánchez et al. (2003).

The presence of the cysts of E. coli and I. butschlii detected in sources of water also revealed that the water had not been properly purified, thus constituting a further risk for parasitic infection (Basualdo et al., 2000). Although the high percentage of intesti- nal protozoa in these children could be attributed to feces-polluted water, protozoa in particular were not associated with SEV. In this sense, Raso et al. (2005) demonstrated that high prevalences of protozoa (i.e. B. hominis, E. nana and I. butschlii) were not indicative of poverty since they were more frequently observed in higher income groups.

The prevalence of undernutrition here was even higher than that observed in other vulnerable populations of Argentina (Bolzán et al., 2005; Calvo and Aguirre, 2005; Orden et al., 2005). It was mainly evidenced by the percentage of stunted children, which prevalence was about $12 \%$ higher than that expected under the distribution of the reference. According to Mercer et al. (2005), height deficits in children are the result of at least two variables: the occurrence of unfavorable socio-environmental circumstances during the early stages of life along with other living experiences transmitted by parents and grandparents and, the progressive deterioration in the living conditions of families over time. These observations were also reported by Oyhenart et al. (2007) in some suburbs of the Gran La Plata including El Paligüe.

In summary, the population surveyed is continuously exposed to infections by intestinal parasites, facilitated by fecal contamination of soil and water, in conjunction with deficient housing conditions. Nevertheless, the study evidences that living conditions are variable within this population. Even among those living in absolute poverty, there seem to be differences in the extent to which parents are able to use their scant resources to influence their children's morbidity. This implies further research from a qualitative approach allowing an understanding of the social practices associated with health care.

\section{Authors' contributions}

Dra. María I. Gamboa: Parasitological and socio-environmental data collection, laboratory analysis and redaction of manuscript. Dra. Graciela T. Navone: Laboratory analysis and redaction of manuscript.

Dra. Alicia B. Orden: Anthropometric survey and redaction of manuscript.

Dra. María F. Torres: Anthropometric survey and redaction of manuscript.

Dr. Luis E. Castro: Statistical analysis.

Dra. Evelia E. Oyhenart: Anthropometric survey and redaction of manuscript.

\section{Acknowledgements}

The authors are grateful to the staff of the Father Cajade Foundation for their valuable assistance during the field work. This research was supported by grants from the Comisión de Investigaciones Científicas de la Provincia de Buenos Aires (CIC), the Consejo Nacional de Investigaciones Científicas y Técnicas (CONICET), the Agencia Nacional de Promoción Científica y tecnológica (ANPCyT) and the Universidad Nacional de La Plata (UNLP).

\section{References}

Almandoz, A., 2008. Despegues sin madurez. Urbanización, industrialización y desarrollo en la Latinoamérica del siglo XX. EURE 34, 61-76.

American Public Health Association, 1999. In: Clescerl, L.S., Greenberg, A.E., Eaton, A.D. (Eds.), Standard Methods for the Examination of Water and Wastewater 20th ed. American Public Health Association, Washington, DC, 1200 pp.

Basualdo, J., Pezzani, B., De Luca, M.M., Córdoba, A., Apezteguía, M., 2000. Screening of the municipal water system of La Plata, Argentina, for human intestinal parasites. Int. J. Hyg. Environ. Health 203, 177-182.

Bethony, J., Brooker, S., Albonico, M., Geiger, S.M., Loukas, A., Diemert, D., Hotez, P.J., 2006. Soil-transmitted helminth infections: ascariasis, trichuriasis, and hookworm. Lancet 367, 1521-1532. 
Bolzán, A., Mercer, R., Ruiz, V., Brawerman, J., Marx, J., Adrogué, G., Carioli, N. Cordero, C., 2005. Evaluación nutricional antropométrica de la niñez pobre del norte argentino: Proyecto encuNa. Arch. Argent. Pediatr. 103, 545-555.

Calvo, E.B., Aguirre, P., 2005. Crisis de la seguridad alimentaria en la Argentina y estado nutricional en una población vulnerable. Arch. Argent. Pediatr. 103, 77-90.

Córdoba, A., Ciarmela, L., Pezzani, B., Gamboa, M., De Luca, M., Minviele, M., Basualdo, J., 2002. Presencia de parásitos intestinales en paseos públicos urbanos en La Plata, Argentina. Parasitol. Latinoam. 57, 25-29.

Dada, B.J., Lindquist, L.J., 1979. Studies of flotation techniques of the recovery of helminth eggs from soil and the prevalence of eggs of Toxocara sp. in some Kansas public places. Am. Vet. Med. Assoc. 174, 1208-1210.

Díaz Malásques, L.R., 2002. Planes de desarrollo local: enfoques y tendencias en América Latina. Rev. Inst. Invest. Fac. Minas. Metal. Cienc. Geogr. 5, 58-64.

Dunn, J.J., Columbus, S.T., Aldeen, W.E., Davis, M., Carroll, K.C., 2002. Trichuris vulpis recovered from a patient with chronic diarrhea and five dogs. J. Clin. Microbiol. 40, 2703-2704.

EPH. Encuesta permanente de hogares, 2003. Instituto Nacional de Estadística y Censos. Secretaría de Política Económica. Ministerio de Economía y Producción. República Argentina. Available at: http://www.indec.mecon.gov.ar.

Gamboa, M.I., 1999. Estudio ecoepidemiológico de la relación enteroparasitosis/ambiente en tres poblaciones infantiles de la ciudad de La Plata. Doctoral Thesis. Facultad de Ciencias Naturales y Museo, UNLP, 242 pp.

Gamboa, M.I., Basualdo, J.A., Córdoba, M.A., Pezzani, B.C., Minvielle, M.C., Lahitte, H.B., 2003. Distribution of intestinal parasitoses in relation to environmental and sociocultural parameters in La Plata, Argentina. J. Helminthol. 77, 15-20.

Krzanowski, W.J., Marriott, F.H.C., 1994. Multivariate Analysis Part I: Distributions, Ordination, and Inference. Edward Arnold, London, England, 280 pp.

Kuczmarski, R.J., Ogden, C.L., Grummer-Strawn, L.M., Flegal, K.M., Guo, S.S., Wei, R., Mei, Z., Curtin, L.R., Roche, A.F., Johnson, C.L., 2000. CDC Growth Charts: United States. Advance Data from Vital and Health Statistics 314. National Center for Health Statistics, Hyattsville, MD, pp. 1-27.

Lohman, T.G., Roche, A.F., Martorell, K.M., 1998. Anthropometric Standardization Reference Manual. Human Kinetics Books, Champaign, IL, pp. 3-70.

Mercer, R., Bolzán, A., Ruiz, V., Brawerman, J., Marx, J., Adrogué, G., Carioli, N., Corder, C., 2005. Encuesta de nutrición de la niñez del norte argentino: Proyecto encuNa Parte II: El estado nutricional y el contexto familiar y social. Arch. Argent. Pediatr. 103, 556-565.

Meulman, J.J., van der Kooij, A.J., Heiser, W.J., 2004. Principal component analysis with nonlinear optimal scaling transformations for ordinal and nominal data. In: Kaplan, D. (Ed.), The SAGE Handbook of Quantitative Methodology for the Social Sciences. Sage, London, pp. 49-70.

Minvielle, M., Taus, M.R., Ciarmela, M.L., Francisconi, M., Barlasina, M., Pezzani, B.C., Gasparovic, A., Raffo, A., Goldaracena, C., 2003. Aspectos epidemiológicos asociados a toxocarosis en Gualeguaychú, Entre Ríos, Argentina. Parasitol. Latinoam. $58,128-130$.

Mirdha, B.R., Singh, Y.G., Samantray, J.C., Mishra, B., 1998. Trichuris vulpis infection in slum children. Indian J. Gastroenterol. 17, 154.

Morales, G., Arelis Pino, L., 1987. Parasitología cuantitativa (Quantity Parasitology). Acta Científica Venezolana, Venezuela, p. 132.
Navone, G.T., Gamboa, M.I., Kozubsky, L., Costas, M.E., Cardozo, M.I., Sisliauskas, M.M., Gonzalez, M., 2005. Estudio comparativo de recuperación de formas parasitarias por diferentes métodos de enriquecimiento coproparasitológico. Parasitol. Latinoam. 60, 170-173.

Navone, G.T., Gamboa, M.I., Oyhenart, E., Orden, B., 2006. Parasitosis intestinales en poblaciones Mbya-Guaraní de la Provincia de Misiones Aspectos epidemiológicos y nutricionales. Cad Saúde Públ. 22, 109-118.

Needham, C., Kim, H.T., Hoa, N.V., Cong, L.D., Michael, E., Drake, L., Hall, A., Bundy, D.A.P., 1998. Epidemiology of soil-transmitted nematode infections in Ha Nam Province, Vietnam. Trop. Med. Int. Health 3, 904-912.

Orden, A.B. Torres, M.F. Luis, M.A., Cesani, M.F., Quintero, A.F. Oyhenart, E.E. 2005. Evaluación del estado nutricional en escolares de bajos recursos socioeconómicos en el contexto de la transición nutricional. Arch. Argent. Pediatr. 103, 205211.

Oyhenart, E.E., Torres, M.F., Quintero, F.A., Luis, M.A., Cesani, M.F., Zucchi, M., Orden, A.B., 2007. Estado nutricional y composición corporal de niños pobres residentes en barrios periféricos de La Plata, Argentina. Rev. Panam. Salud Publica. 22 194-201.

PAHO (Pan American Health Organization), 1998. Health in the Americas. World Health Organization, Washington, DC, Scientific Publication No. 569.

Raso, G., Utzinger, J., Silué, K.D., Ouattara, M., Yapi, A., Toty, A., Matthys, B., N'Goran, E.K., 2005. Disparities in parasitic infections, perceived ill health and access to health care among poorer and less poor schoolchildren of rural Côte d'Ivoire. Trop. Med. Int. Health 10, 42-57.

Ruel, M.T., 2000. Urbanization in Latin America: constraints and opportunities for child feeding and care. Food Nutr. Bull. 21, 2-24 (special issue on processed complementary foods in Latin America).

Sánchez, P., Jensen, O., Mellado, I., Torrecillas, C., Raso, S., Flores, M., Minvielle, M.C., Basualdo, J.A., 2003. Presence and persistence of intestinal parasites in canine fecal material collected from the environment in the Province of Chubut, Argentine Patagonia. Vet. Parasitol. 117, 263-269.

Stephenson, L.S., Holland, C.V., 1987. The impact of helminth infections of human nutrition. J. Parasitol. 76, 312-1312.

Thompson, R.C.A., 2001. The future impact of societal and cultural factors on parasitic diseases. Some emerging issues. Int. J. Parasitol. 31, 949-959.

Traub, R.J., Robertson, I.D., Irwin, P., Mencke, Nm., Monis, P., Thompson, R.C., 2003. Humans, dogs and parasitic zoonoses-unravelling the relationships in a remote endemic community in northeast India using molecular tools. Parasitol. Res. 90, $156-157$.

Ulijaszek, S.J., Kerr, D.A., 1999. Anthropometric measurement error and the assessment of nutritional status. Br. J. Nutr. 82, 165-177.

Venturini, L., Radman, N., 1988. Frecuencia de Toxocara canis, Ancylostoma caninum y Giardia sp. según sexo y la edad, en caninos de La Plata (Bs. As., Argentina). Rev. Med. Vet. 69, 161-165.

World Health Organization, 1991. Basic Laboratory Methods in Medical Parasitology World Health Organization, Geneva.

WHO Multicentre Growth Reference Study Group, 2006. WHO Child Growth Standards: Length/Height-for-age, Weight-for-age, Weight-for-height and Body Mass Index-for-age: Methods and Development. World Health Organization, Geneva. 